\title{
CALCOCO2 silencing represents a potential molecular therapeutic target for glioma
}

Zhisen Tian ${ }^{1}$, Cong Ning ${ }^{2}$, Changfeng Fu², Feng Xu², Congcong Zou², Qingsan Zhu ${ }^{1}$, Jun Cai ${ }^{3}$, Yuanyi Wang ${ }^{2}$

\author{
${ }^{1}$ Department of Orthopaedics, China-Japan Union Hospital of Jilin University, \\ Changchun, China \\ ${ }^{2}$ Department of Spine Surgery, The First Hospital of Jilin University, Changchun, China \\ ${ }^{3}$ Paediatric Research Institute, Department of Paediatrics, University of Louisville \\ School of Medicine, Louisville, KY, USA
}

Submitted: 11 December 2019

Accepted: 9 April 2020

Arch Med Sci

DOI: https://doi.org/10.5114/aoms.2020.95880

Copyright (c) 2020 Termedia \& Banach

\section{Abstract}

Introduction: Glioma is the most common primary intracranial tumour that is highly resistant to conventional therapeutic approaches including surgical resection, radiation therapy, and chemotherapy. As a promising alternative treatment, gene therapy has achieved variable degrees in both pre-clinical models and clinical trials.

Material and methods: In our present research, the role of calcium binding and coiled-coil domain 2 (CALCOCO2) in the pathogenesis and progression of glioma was investigated in human glioma U87 and U251 cell lines. In both cell lines, $\mathrm{CALCOCO} 2$ is highly expressed. Targeted by lentivirus vectors, the CALCOCO2 gene was successfully silenced in U87 and U251 cell lines. Both cell counting and MTT assay showed the inhibition of cell growth and cell proliferation in CALCOCO2-silenced glioma cell lines.

Results: Flow cytometry (FCM) and caspase $3 / 7$ measurements indicated that the silencing of $C A L C O C O 2$ gene could also promote cell apoptosis in both cell lines. The underlying mechanism was further explored by gene microarray and western blotting. The CALCOCO2 gene is strongly related to cancer by affecting the expression of hundreds of genes. Among which, the silencing of CALCOCO2 significantly upregulated the pro-apoptosis genes FAS and CASP1 and downregulated the autophagy-related gene BECN1. These data suggest that by regulating FAS, CASP1, and BECN1, the silencing of CALCOCO2 suppresses the growth and proliferation of U87 and U251 glioma cell lines.

Conclusions: The CALCOCO2 could be a potential target for glioma genetic therapy.

Key words: glioma, autophagy, gene silencing, molecular mechanisms.

\section{Introduction}

A glioma is a type of malignant tumour that occurs in the neuroectoderm of the central nervous system with high morbidity, mortality, and recurrence rates [1]. It is the most common primary intracranial tumour, with an annual incidence of 3-10 per 100,000 in the United States, accounting for $46 \%$ of intracranial tumours and $2 \%$ of all malignant tumours [2, 3]. Current predominant treatments are surgical resection, radiation therapy, and chemotherapy [4-6]. However, due to the invasion and metastasis proper-

\author{
Corresponding authors: \\ Qingsan Zhu \\ Department of Orthopaedics \\ China-Japan Union Hospital \\ of Jilin University \\ Changchun, 130033, China \\ Phone: +86 43184995999 \\ E-mail: zhuqs99@163.com \\ Yuanyi Wang \\ Department of Spine Surgery \\ The First Hospital \\ of Jilin University \\ Changchun 130021, China \\ Phone: +86 43188782222 \\ Email: tedwangyy@hotmail. \\ com \\ Jun Cai \\ Paediatric Research Institute \\ Department of Paediatrics \\ University of Louisville \\ School of Medicine \\ Louisville, KY 40202, USA \\ Phone: +1-502-852-3771 \\ E-mail: jun_cai@tom.com
}


ties of gliomas, it is difficult to attain total removal by surgical resection [7]. In addition, the resistance to radiotherapy and chemotherapy frequently lead to the progression and recurrence of tumours [8]. The prognosis of patients with high-grade glio$\mathrm{ma}$ is still poor, with a median survival time of 14 months [9]. However, gene therapy has emerged as a promising treatment for glioma, with fewer side effects and greater specificity compared to those of traditional therapies. Therefore, it is necessary to identify therapeutic targets based on the molecular mechanisms underlying tumour occurrence and progression for effective glioma treatment.

Autophagy is a homeostatic process in which cellular metabolic waste is recycled to support cellular metabolism via autophagosomes [10, 11]. Recently, researchers have proven that autophagy can promote tumour growth. Activated autophagy is a mechanism by which tumour cells adapt to extreme conditions, such as hypoxia and high metabolic demand [12]. Autophagy occurs during glioma chemoresistance after the use of temozolomide, contributing to the failure of chemotherapy. Drugs targeting autophagy in glioma are urgently needed. CALCOCO2 encodes a coiled-coil domain-containing protein [13]. The protein can combine with ubiquitin-coated bacteria, recognise microtubule-associated protein 1 light chain 3 (LC3) in autophagy, and deliver bacteria to autophagosomes for elimination [14]. However, the role of CALCOCO2 in glioma is unclear.

In this study, the role of CALCOCO2 in the pathogenesis and progression of glioma was investigated.

\section{Material and methods}

\section{Cell culture}

Human glioma U87 and U251 cell lines were obtained from the Shanghai Institute of Cell Biology, Chinese Academy of Sciences. The cells were cultured in DMEM supplemented with $10 \%$ FBS and $1 \%$ antibiotics at $37^{\circ} \mathrm{C}$ with $5 \% \mathrm{CO}_{2}$.

The present study was approved by the Ethics Committee of China-Japan Union Hospital of Jilin University and The First Hospital of Jilin University.

\section{CALCOCO2 expression in glioma cell lines}

CALCOCO2 expression in four glioma cell lines, i.e., U87, U251, U373, and A-172, was assessed by quantitative real-time polymerase chain reaction (RT-qPCR). Briefly, total messenger RNAs (mRNAs) of cells were extracted using TRIzol reagent (Invitrogen, Carlsbad, CA, USA). The mature mRNAs (2 $\mu$ g per sample) were reverse transcribed into cDNAs using Super MMLV reverse transcriptase (BioTeke, Beijing, China). The mRNA levels of CALCOCO2 were determined by RT-qPCR using the
Bio-Rad Connect Real-time PCR platform. RT-qPCR consisted of an initial denaturation step at $95^{\circ} \mathrm{C}$ for $15 \mathrm{~s}, 30$ cycles of $95^{\circ} \mathrm{C}$ for $5 \mathrm{~s}$, and $60^{\circ} \mathrm{C}$ for $30 \mathrm{~s}$. The mRNA expression levels were determined by a comparative CT $\left(2^{-\Delta \Delta C t}\right)$ analysis.

\section{Construction of lentivirus vectors targeting CALCOCO2}

A short hairpin RNA (shRNA) was designed according to the sequence of CALCOCO2. The shRNA oligos were synthesised and inserted into the plasmid GV115 (GeneChem, Shanghai, China), and then recombinant lentiviruses were constructed by plasmid co-transfection of 293T cells according to the manufacturer's instructions. The viral supernatant was collected and filtered through a $0.45-\mu \mathrm{m}$ filter (Millipore, Billerica, MA, USA) at $72 \mathrm{~h}$ post-transfection, and the viral titre was determined. Subsequently, the viral supernatant was added to the U87 and U251 cell lines, and the expression of CALCOCO2 in cells was observed under a fluorescence microscope at $48 \mathrm{~h}$ (Olympus America, Melville, NY, USA). The cells infected with shCALCOCO2 and control shRNA were termed shCALCOCO2 and shControl, respectively.

\section{Silencing efficiency assessment}

The silencing efficiency of CALCOCO2 at the protein level was assessed by western blotting. Briefly, after U87 and U251 cells were infected with shCALCOCO2 or shControl for 5 days, they were collected and lysed with protein lysate $(100 \mathrm{mM}$ tris(hydroxymethyl)aminomethane hydrochloride ( $\mathrm{pH} 6.8$ ), $10 \mathrm{mM}$ ethylenediaminetetraacetic acid, and 4\% sodium dodecyl sulphate) for $20 \mathrm{~min}$. The lysates were centrifuged, and the supernatants were collected. The total protein was measured by a BCA protein assay (HyClone-Pierce, Rockford, IL, USA), separated by $12.5 \%$ sodium dodecyl sulphate polyacrylamide gel electrophoresis, transferred to polyvinylidene difluoride membranes, and blocked for $1 \mathrm{~h}$ at room temperature $\left(25^{\circ} \mathrm{C}\right)$. The membranes were then incubated with rabbit anti-GAPDH or rabbit anti-CALCOCO2 primary antibodies (1: 500; Santa Cruz Biotechnology, Santa Cruz, CA, USA) and incubated at $4^{\circ} \mathrm{C}$ overnight. The membranes were washed with Tris-buffered saline and Tween, and a moderate volume of secondary antibody (goat anti-mouse IgG, 1 : 5000; Santa Cruz Biotechnology) was added and incubated for $3 \mathrm{~h}$ at room temperature. The membranes were then detected using enhanced chemiluminescence $(E C L)$ reagent (ECL-Plus/Kit; Amersham, Piscataway, NJ, USA).

\section{Cell counting}

Multiparametric high-content screening (HCS) was utilised to determine the cell growth status. 
Briefly, U87 and U251 cells in the logarithmic phase in shCALCOCO2 or shControl groups were seeded on 96-well plates at a density of 4000 cells/well. Subsequently, the cells were incubated for five days, and every day the living cells exhibiting green fluorescence in each plate were recognised and counted using ArrayScan ${ }^{\mathrm{TM}}$ HCS software (Cellomics Inc., Pittsburgh, PA, USA).

\section{MTT assay}

A3-(4,5-dimethylthiazol-2-yl)-2,5-diphenyl-tetrazoniumbromide (MTT) assay was performed to assess cell viability. Briefly, the exponential growth cells infected with shCALCOCO2 or shControl were seeded on 96-well plates at a density of 4000 cells/well and incubated for 1, 2, 3, 4, or 5 days. At a predetermined timepoint, $20 \mu \mathrm{l}$ of MTT was added to the cells, followed by incubation for $4 \mathrm{~h}$. The supernatants were removed, and $100 \mu \mathrm{l}$ of dimethyl sulphoxide (DMSO) was added to decompose formazan. The viability of cells was analysed by detecting absorbance at $490 \mathrm{~nm}$ using a microplate reader (BioTek Instruments, Winooski, VT, USA).

\section{Flow cytometry}

U87 and U251 cells infected with shCALCOCO2 or shControl were seeded on six-well plates after lentivirus infection for 5 days at a density of $3 \times$ $10^{5}$ and cultured for $48 \mathrm{~h}$. Subsequently, the cells were harvested, centrifuged, washed with PBS twice, and then resuspended using staining buffer at a cell concentration of $1.0 \times 10^{6} / \mathrm{ml}$. The cell suspensions were then stained with Annexin and $\mathrm{PI}$ at room temperature for $15 \mathrm{~min}$ in the dark and evaluated by flow cytometry (FCM, FACSCalibur; BD Biosciences, Franklin Lakes, NJ, USA).

\section{Caspase-Glo 3/7 assay}

Caspase-Glo $3 / 7$ reagent was prepared by mixing caspase-Glo $3 / 7$ with the substrate and was then stored at $4^{\circ} \mathrm{C}$. Cells transfected with shCALCOCO2 or shControl at the logarithmic phase were seeded on 96-well plates at a density of 4000 cells/well and then cultured for 1, 2, 3, 4, or 5 days. The caspase-Glo 3/7 reagent was added to the cells at an amount equivalent to the volume of the culture, shaken for $30 \mathrm{~s}$, and cultured for $0.5-3 \mathrm{~h}$ at room temperature according to cell conditions. The fluorescence of each well was assessed using a microplate reader.

\section{Gene microarray}

The genome-wide effect of the silencing of CALCOCO2 in the U87 cell line was investigated using a GeneChip ${ }^{\oplus}$ PrimeView $^{\text {TM }}$ Human Gene Ex- pression Array (Affymetrix; Thermo Fisher Scientific, Inc., Waltham, MA, USA). Briefly, after cells were treated with shControl or shCALCOCO2 for $72 \mathrm{~h}$, the total mRNA was extracted, quantified, reverse-transcribed, and labelled with biotin using the GeneChip ${ }^{\circledast}$ 3' IVT Express Kit (Thermo Fisher Scientific). Subsequently, the labelled cDNAs were used to hybridise the GeneChip ${ }^{\circledast}$ PrimeView $^{\mathrm{TM}} \mathrm{Hu}$ man Gene Expression Array consisting of 20,000 genes according to the manufacturer's protocol. After hybridisation, the gene chips were washed and scanned using a GeneChip ${ }^{\oplus}$ Fluidics Station 450, and images were acquired using GeneChip operating software. Data were summarised, and GeneSpring software was used for data analysis. Differentially expressed genes generated from the microarray analyses were analysed by the Ingenuity Pathway Core Analysis (IPA ${ }^{\oplus}$, QIAGEN, Redwood City, CA, USA) to interpret the underlying molecular mechanisms. The enrichment of gene networks was analysed based on the overlap score ( $p$-value and $z$-score). Three main analyses were performed using IPA, i.e. analyses of diseases and functions, gene networks, and downstream targets.

\section{Assessment of downstream target proteins}

To investigate the role of $\mathrm{CALCOCO} 2$ in the pathogenesis of glioma, the expression levels of related proteins in U87 and U251 cells infected with shCALCOCO2 or shControl were assessed by western blotting. The specific methods were as described above, and the protein levels were measured.

\section{Statistical analyis}

All experiments were repeated thrice and the results expressed as means \pm standard deviation. Statistical differences were evaluated using paired Student's $t$-tests implemented in SPSS 23.0 (SPSS Inc., Chicago, IL, USA). $P<0.05$ indicated statistical significance, and $p<0.01$ and $p<0.001$ were considered highly significant.

\section{Results}

\section{CALCOCO2 expression in glioma cells and the silencing of CALCOCO2 in U87 and U251 cell lines}

As shown in Figure $1 \mathrm{~A}$, CALCOCO2 mRNA was overexpressed in all four cell lines, and the expression was highest in U87 and U251 cells. Moreover, as shown in Figures 1 B and C, most U87 and U251 cells were positive for green fluorescent protein under a microscope, indicating the efficient silencing of CALCOCO2 in both cell lines. The relative CALCOCO2 mRNA levels for shCALCOCO2-treated cells were $0.138 \pm 0.014$ and $0.375 \pm 0.025$ for 
A

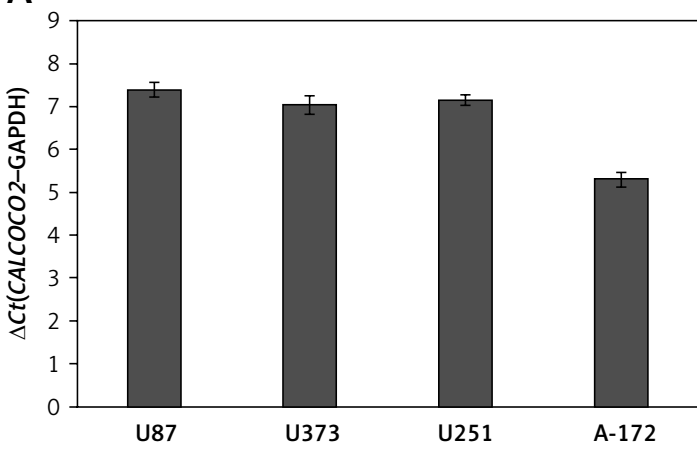

C
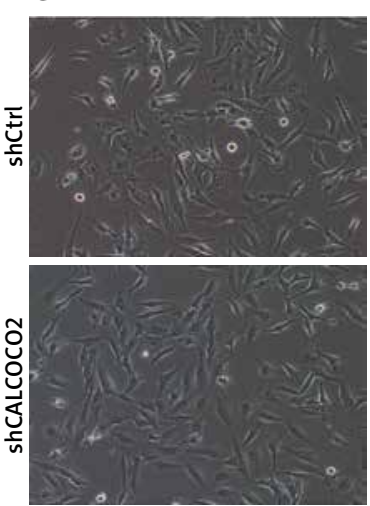

E

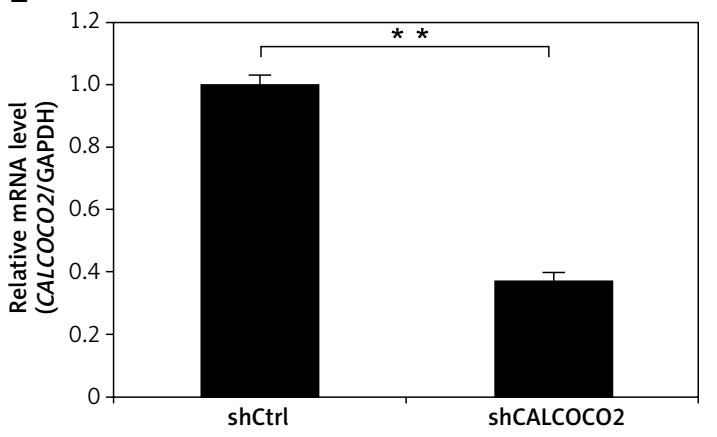

B
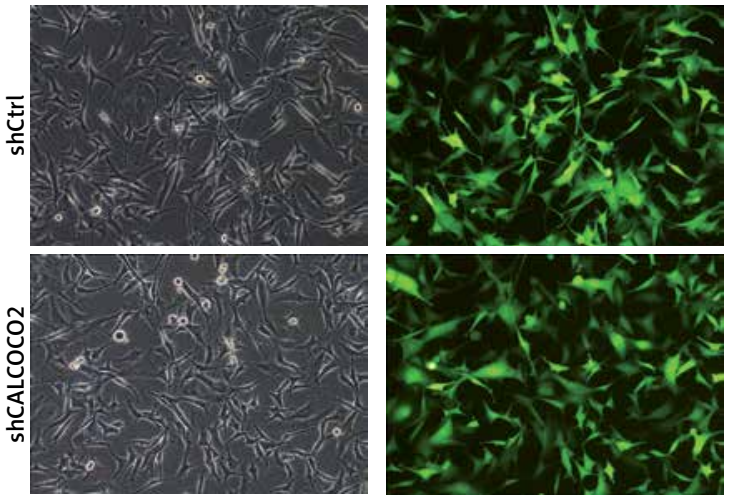

D

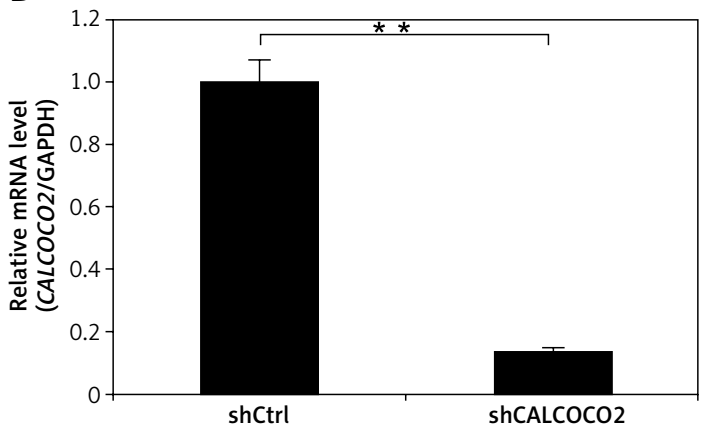

$\mathrm{F}$

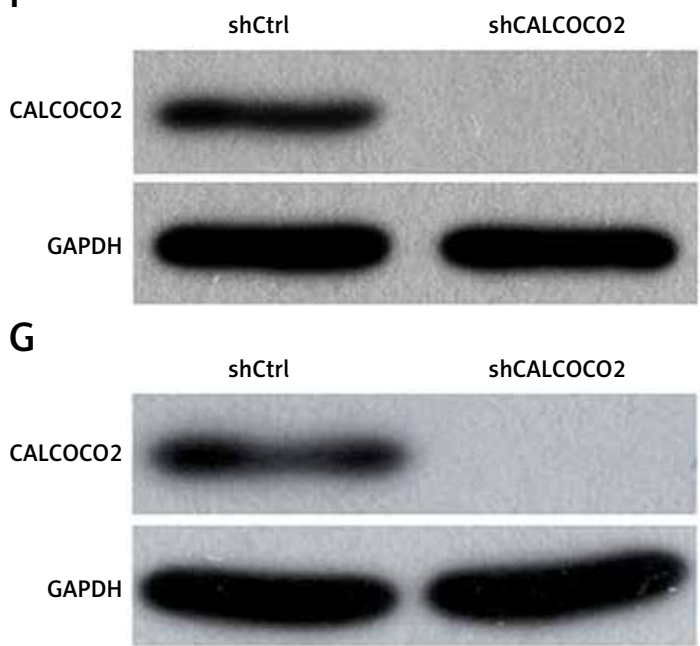

Figure 1. CALCOCO2 silencing in the U87 and U251 cell lines. A - Expression of CALCOCO2 in glioma cell lines. qRT-PCR was performed to evaluate the expression levels of CALCOCO2 in four glioma cell lines (U87, U251, U373, and A-172). B, C - Microscopic images of U87 and U251 cell lines in the shControl and shCALCOCO2 groups. D, E - qRT-PCR analysis of the efficiency of CALCOCO2 silencing at the mRNA level. F, G - Western blot analysis of the efficiency of CALCOCO2 silencing at the protein level

Data are shown as means $\pm S D\left(n=5 ;^{*} p<0.05,{ }^{* *} p<0.01\right.$, and $\left.{ }^{* * *} p<0.001\right)$.

the U87 and U251 cell lines, respectively, which were significantly lower than those of shControl cells $(1.002 \pm 0.071$ and $1 \pm 0.032$, respectively, $p<0.001$; Figures 1 D, E). Consistent with these findings, the protein levels of CALCOCO2 were significantly downregulated compared with those in shControl U87 and U251 cells (Figures 1 F, G).
Effects of CALCOCO2 silencing on cell growth

As shown in Figure $2 \mathrm{~A}, \mathrm{CALCOCO} 2$ silencing significantly inhibited U87 cell growth compared to that of the shControl group $(p<0.05)$. The cell counting results showed that the proliferation fold change values for the shCALCOCO2 group in the $U 87$ cell line at days 4 and 5 were $2.8 \pm 0.07$ 
A

Day 1
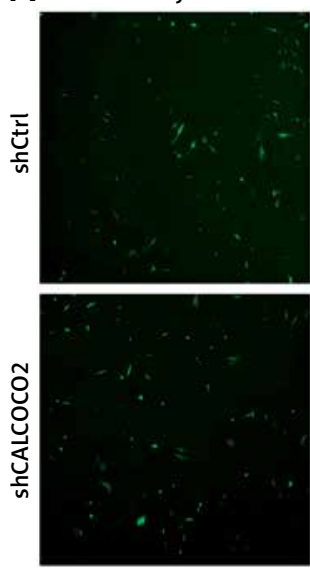

B
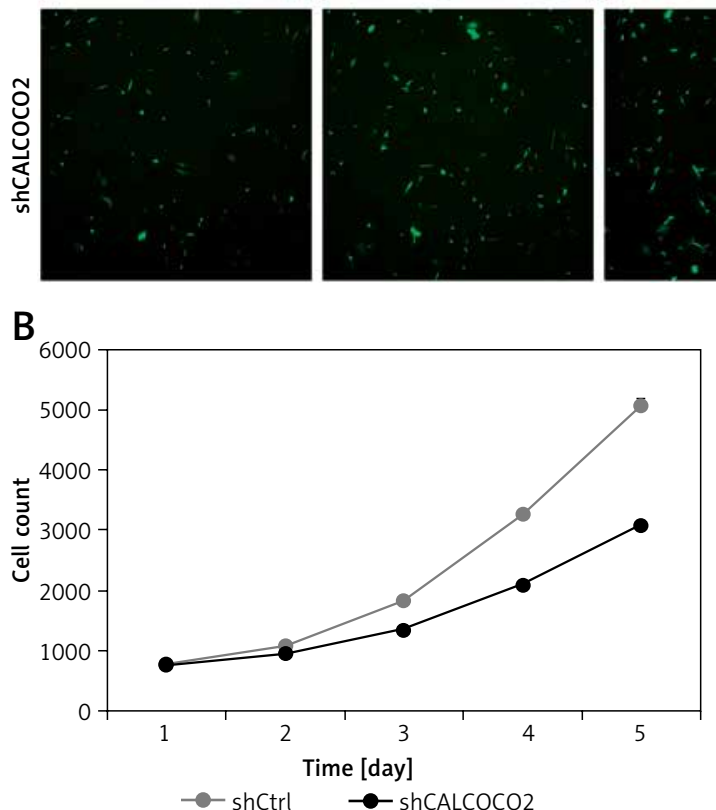

Day 3
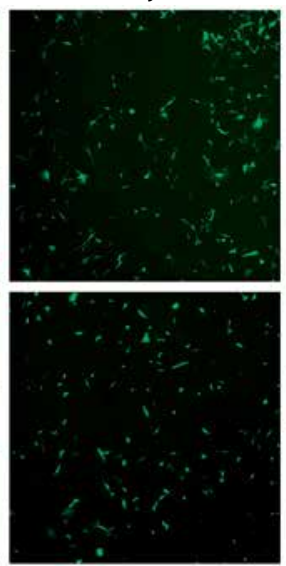

C

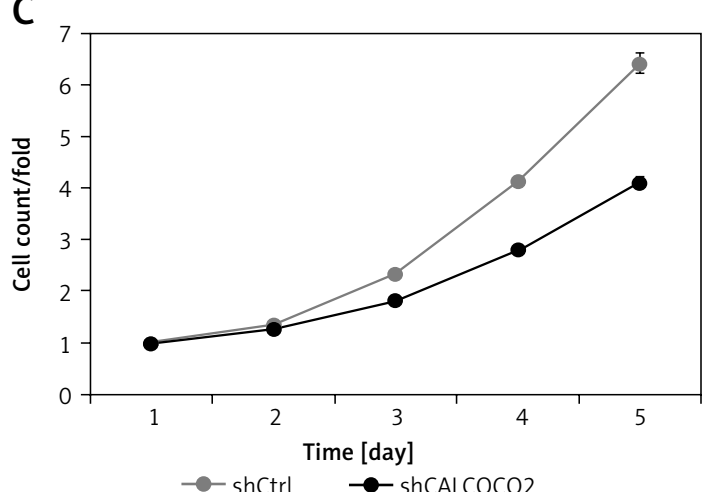

Day 3
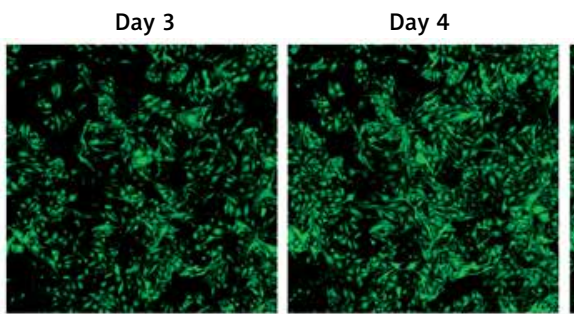

Day 5
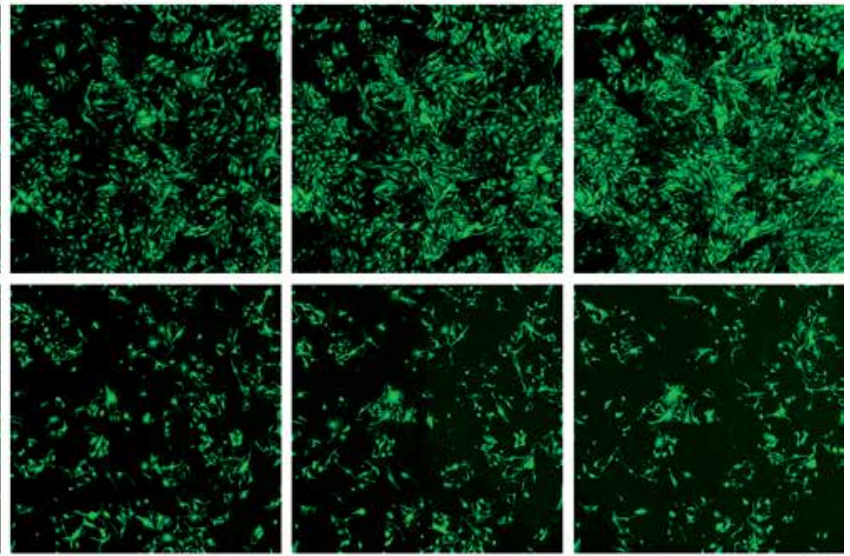

$\mathrm{E}$

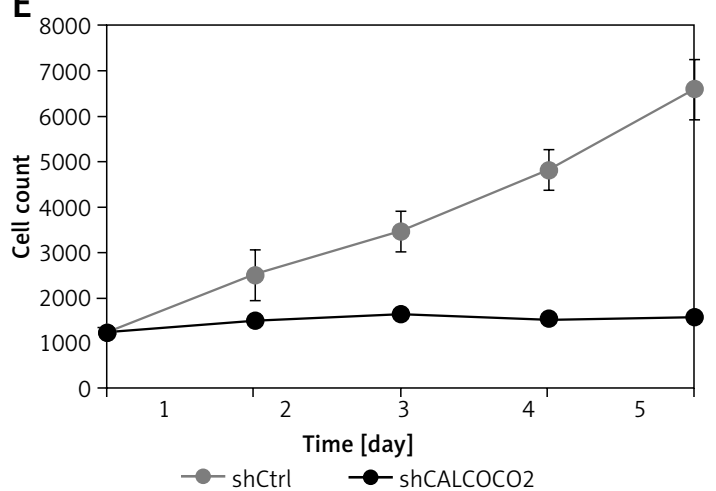

$\mathrm{F}$

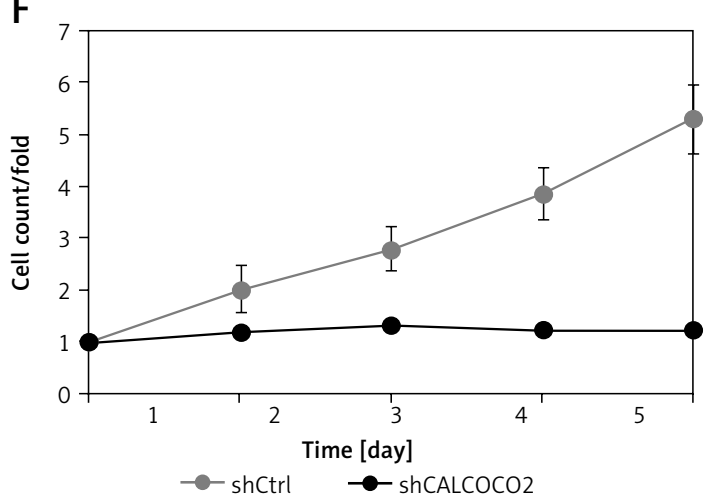

Figure 2. Silencing of CALCOCO2 inhibited the proliferation of both U87 and U251 cells. A - Representative images of HCS analysis of U87 cell lines in the shControl and shCALCOCO2 groups at various timepoints after lentivirus infection. B, C - Statistical analysis of cell numbers for the U87. D - Representative images of HCS analysis of U251 cell lines in the shControl and shCALCOCO2 groups at various timepoints after lentivirus infection. $\mathrm{E}, \mathrm{F}-\mathrm{Statistical}$ analysis of cell numbers for the U87 cell lines

HCS - multiparametric high-content screening. 

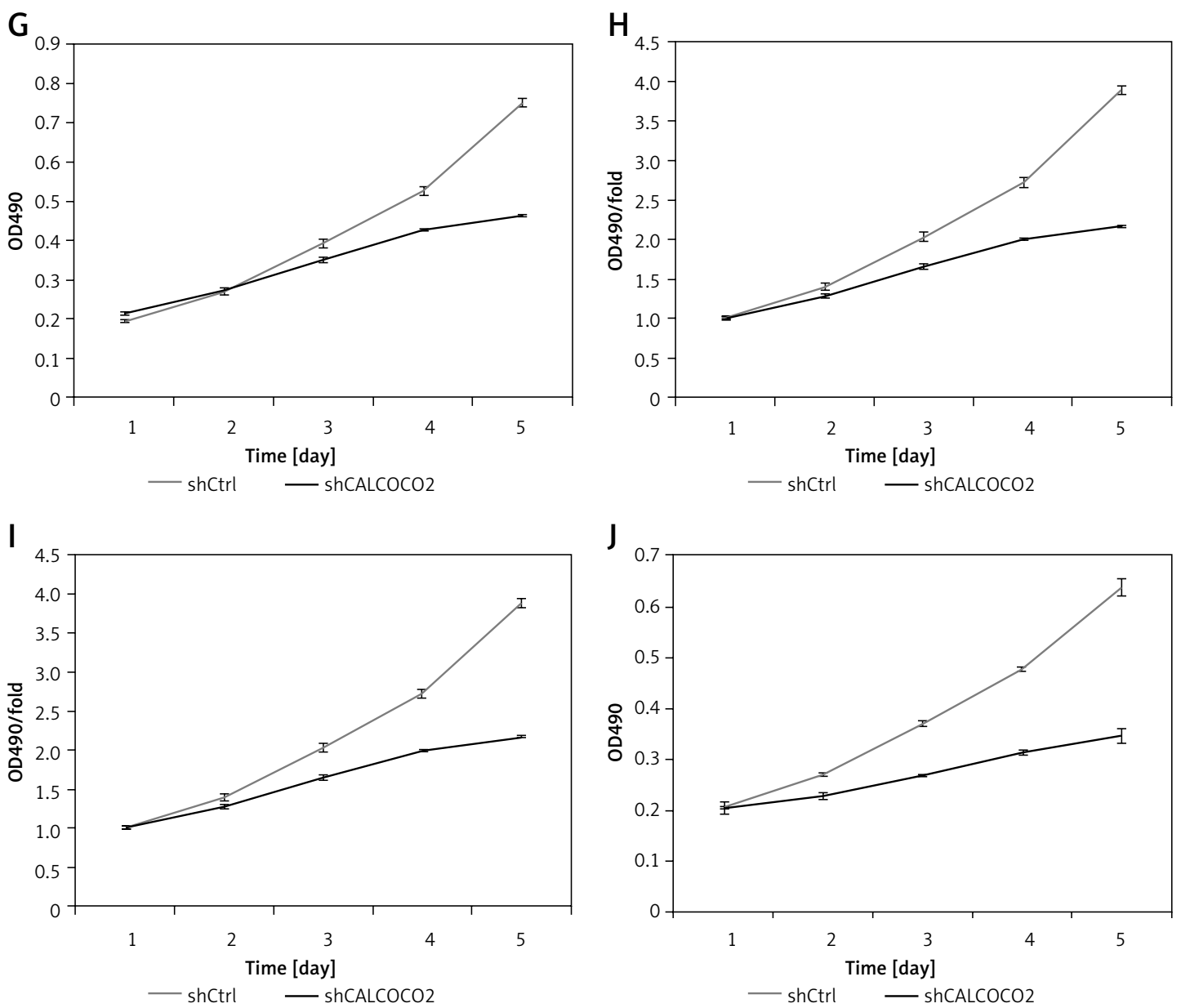

Figure 2. Cont. G-J - Cell viability of the U87 and U251 cell lines in the shControl and shCALCOCO2 groups was analysed by MTT assay

HCS - multiparametric high-content screening.

and $4.1 \pm 0.11$, respectively, which were obviously lower than those for shControl cells $(4.13 \pm 0.05$ and $6.42 \pm 0.2$, respectively). Similarly, there was a significant difference in cell counts between the shCALCOCO2 and shControl groups in the U251 cell line, especially on days 4 and 5 , indicating the inhibitory effect of CALCOCO2 silencing on cell growth. An MTT assay also showed that both U87 and U251 cells exhibited slower proliferation and growth after the silencing of CALCOCO2, and these effects were even more pronounced on day 5 , when the proliferation fold changes in the shCALCOCO2 group were $2.163 \pm 0.0068$ and $1.696 \pm 0.0672$ in U87 and U251 cells, respectively, while the proliferation fold changes in the shControl group were $3.882 \pm 0.0547$ and $3.117 \pm 0.0793$, respectively.

\section{Effects of CALCOCO2 silencing on cell apoptosis}

As shown in Figures $3 \mathrm{~A}-\mathrm{D}$, the percentages of cell apoptosis in shCALCOCO2-infected U87 and U251 cell lines, as detected by FCM, were
$11.44 \pm 0.1178 \%$ and $9.32 \pm 0.0955 \%$, respectively, on day 4 post-CALCOCO2 silencing, while the shControl group exhibited significantly decreased apoptotic percentages of $4.13 \pm 0.1308 \%$ and $4.3 \pm 0.1 \%$, respectively $(p<0.001)$. In addition, caspase $3 / 7$ measurements showed that the expression levels of caspase $3 / 7$ were approximately 1.72 and 2.07 times greater than those in the shControl group for U87 and U251 cells after infection with shGATAD2A for 3 days (Figures 3 E, F).

\section{Molecular mechanisms underlying the effects of CALCOCO2 in gliomas}

In the gene microarray analysis, there were 586 differentially expressed genes, including 357 genes that were downregulated and 229 genes that were upregulated (Figure $4 \mathrm{~A}$ ). These discriminative genes were functionally analysed by IPA. As shown in Figure 4 B, 17 CALCOCO2-related functions and diseases were detected by IPA, and infectious diseases, cancer, organismal injury, and abnormalities were the highest ranked categories. The gene in- 

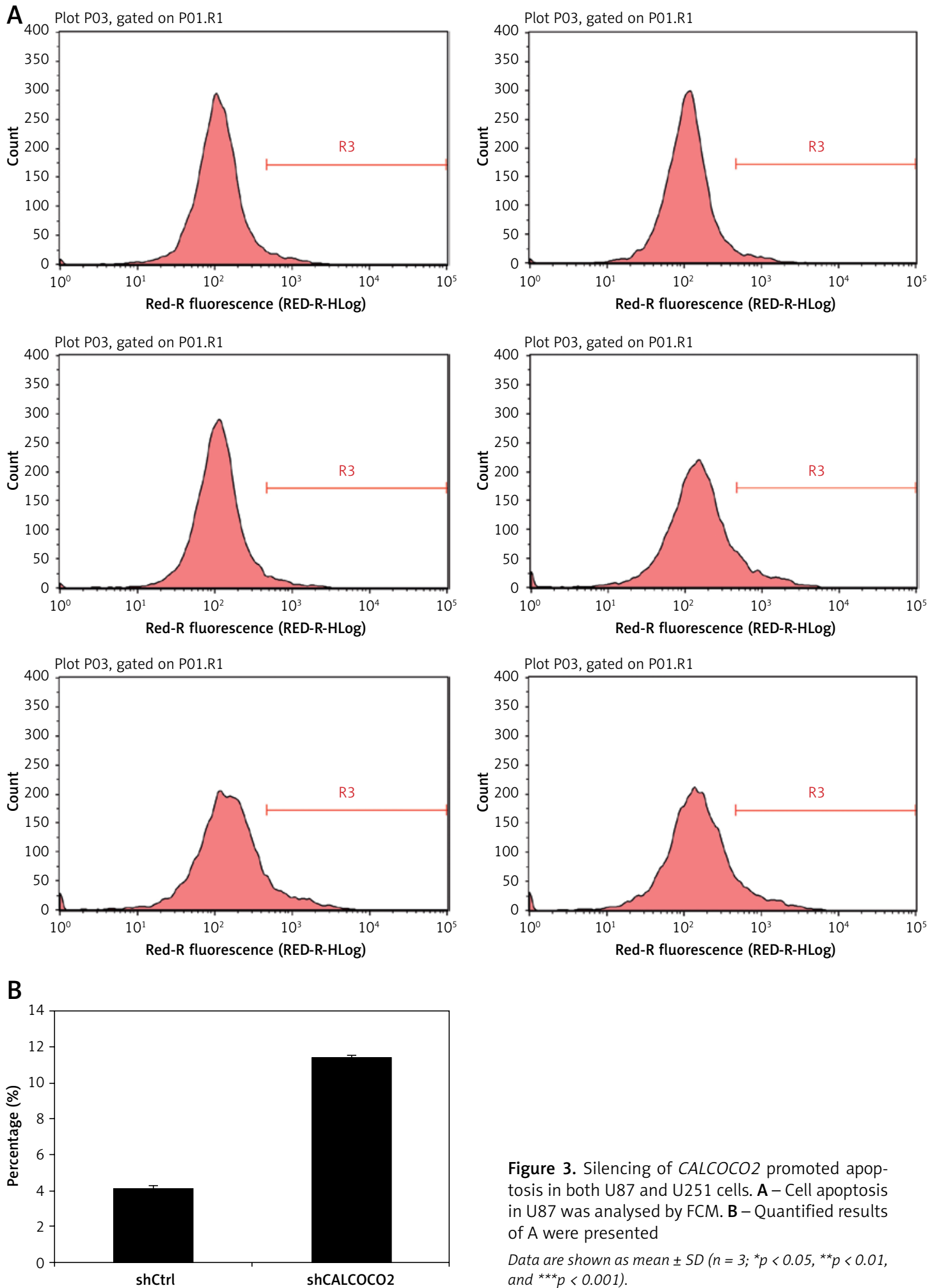

teraction network confirmed these results (Figure $4 \mathrm{C}$ ). The silencing of CALCOCO2 markedly upregulated CASP1, FMR1, GSK3B, BECR5, CHEK1, and $F A S$ and downregulated the other loci (Figure $4 \mathrm{D}$ ). The expression levels of BBECN1, CASP1, FAS, GSK3B, BIRC5, and IL-1 $\beta$ were further analysed by western blotting (Figure $4 \mathrm{E}$ ).

Figure 3. Silencing of $\mathrm{CALCOCO} 2$ promoted apoptosis in both U87 and U251 cells. A-Cell apoptosis in U87 was analysed by FCM. B - Quantified results of A were presented

Data are shown as mean $\pm S D\left(n=3 ;{ }^{*} p<0.05,{ }^{* *} p<0.01\right.$, and $\left.{ }^{* * *} p<0.001\right)$.

\section{Discussion}

CALCOCO2 is a coiled-coil domain-containing protein-coding gene with an important role in autophagy [15]. It serves as an autophagy receptor that interacts with targets and transfers them to autophagosomes by binding to LC3. The abnormal expression of CALCOCO2 is related to inflamma- 

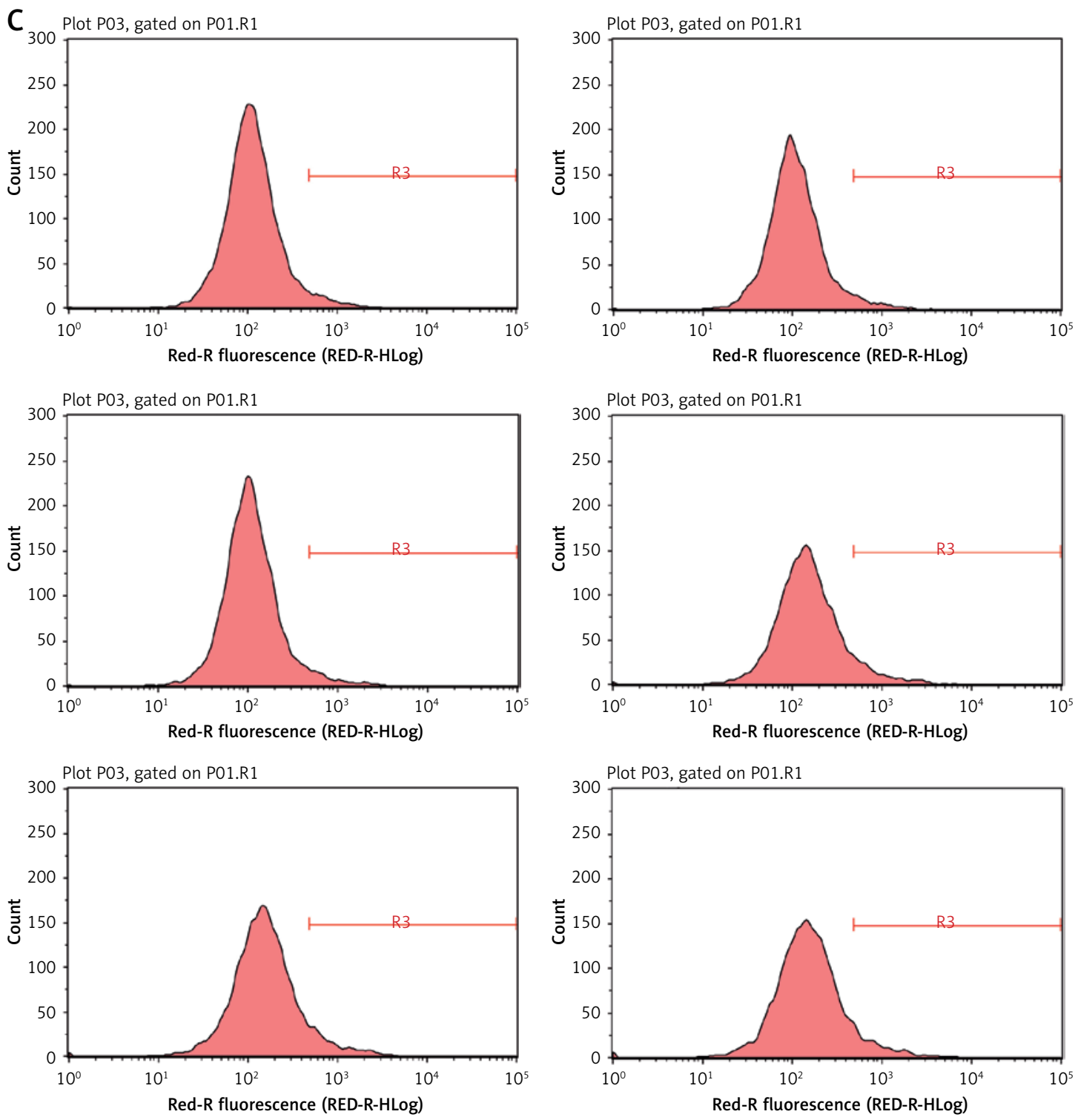

D

\section{E}
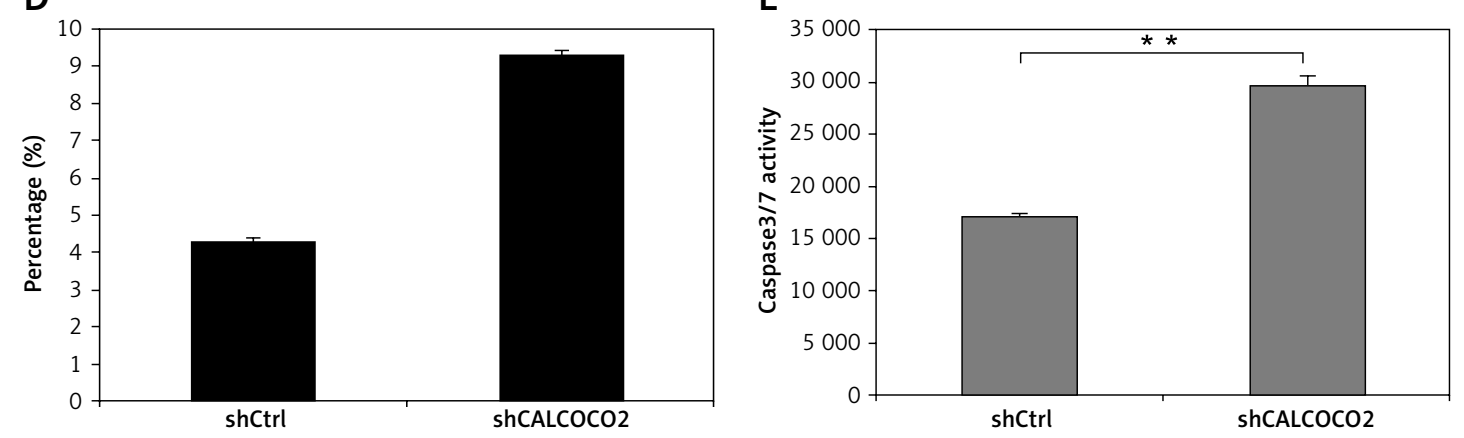

F

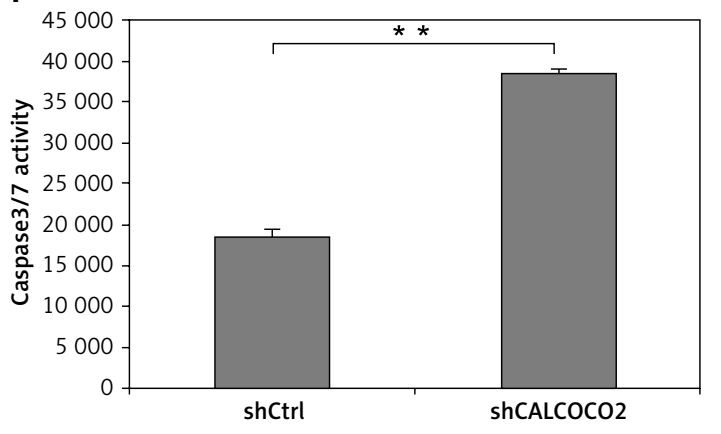

Figure 3. Cont. C - Cell apoptosis in U251 was analysed by FCM. D - Quantified results of A were presented. E, F - Caspase 3/7 activity assays of U87 and $\mathrm{U} 251$ cells

Data are shown as mean $\pm S D\left(n=3 ;{ }^{*} p<0.05,{ }^{* *} p<0.01\right.$, and ${ }^{* *} p<0.001$. 
A

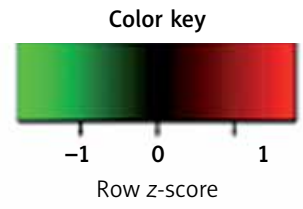

CALCOCO2 silencing represents a potential molecular therapeutic target for glioma

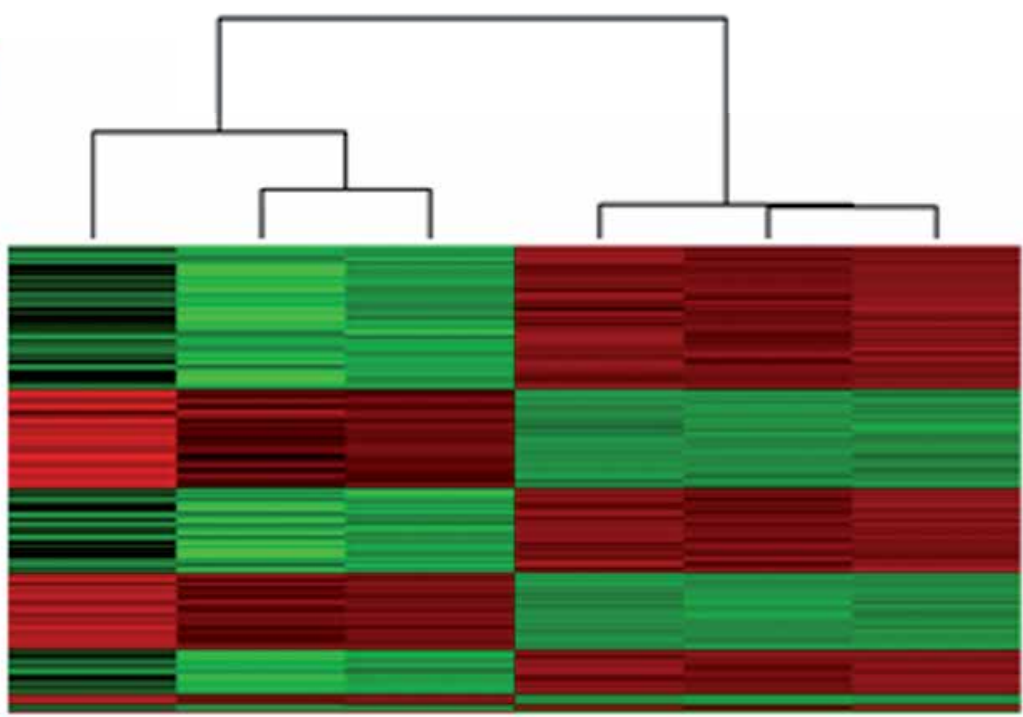

B
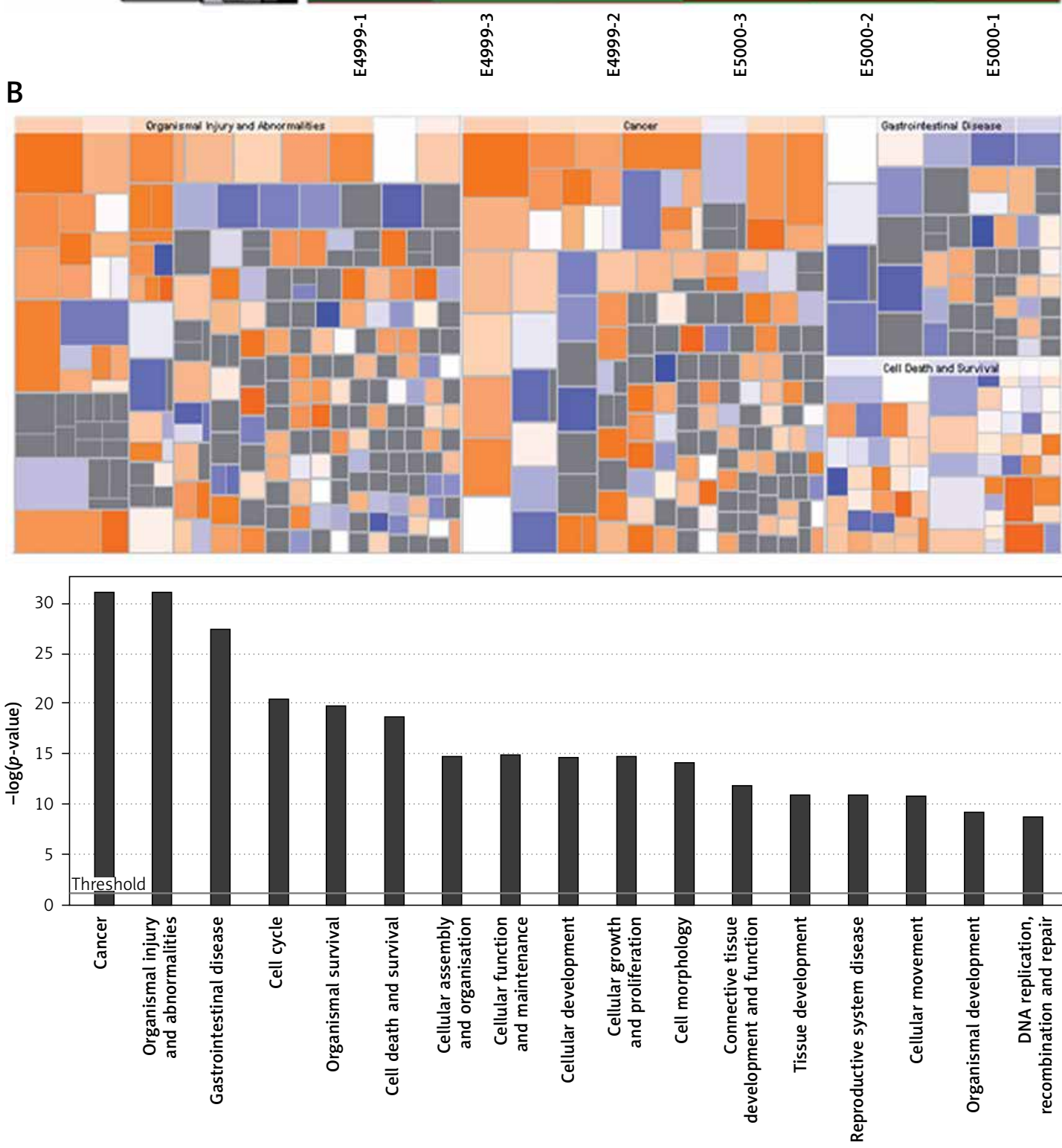

Figure 4. Molecular mechanism underlying the effect of CALCOCO2 in glioma pathogenesis and progression. A-D - IPA analysis of differentially expressed genes obtained from the microarray analysis. A - Heat map of differentially expressed genes. $\mathbf{B}-Z$-scores of related functions and diseases

Data are shown as mean $\pm S D\left(n=3 ;{ }^{*} p<0.05,{ }^{* *} p<0.01\right.$, and $\left.{ }^{* * *} p<0.001\right)$. 
C

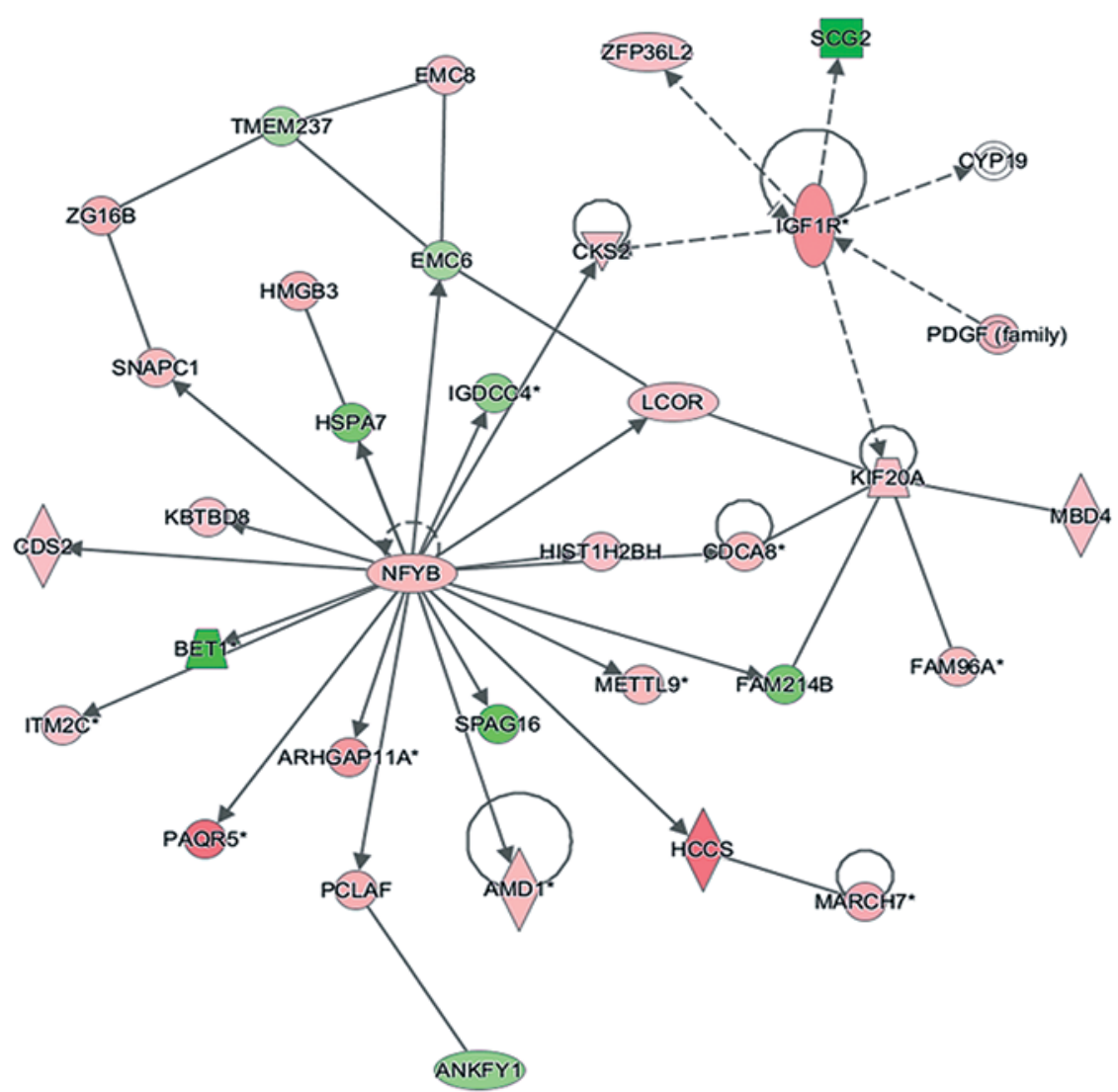

D

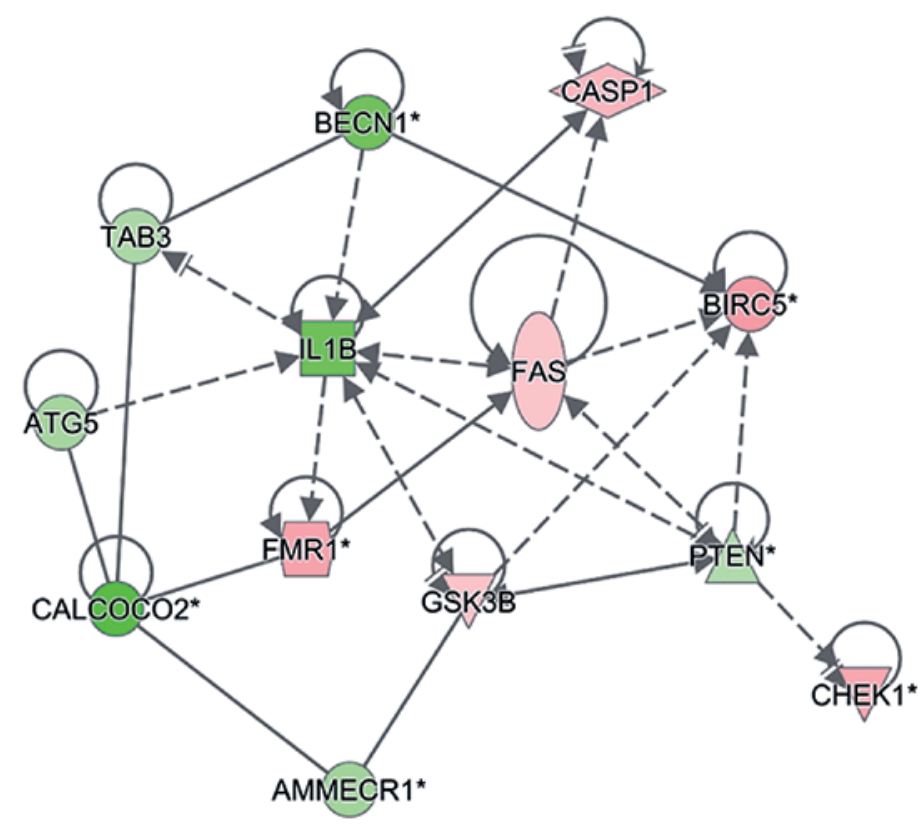

$E$

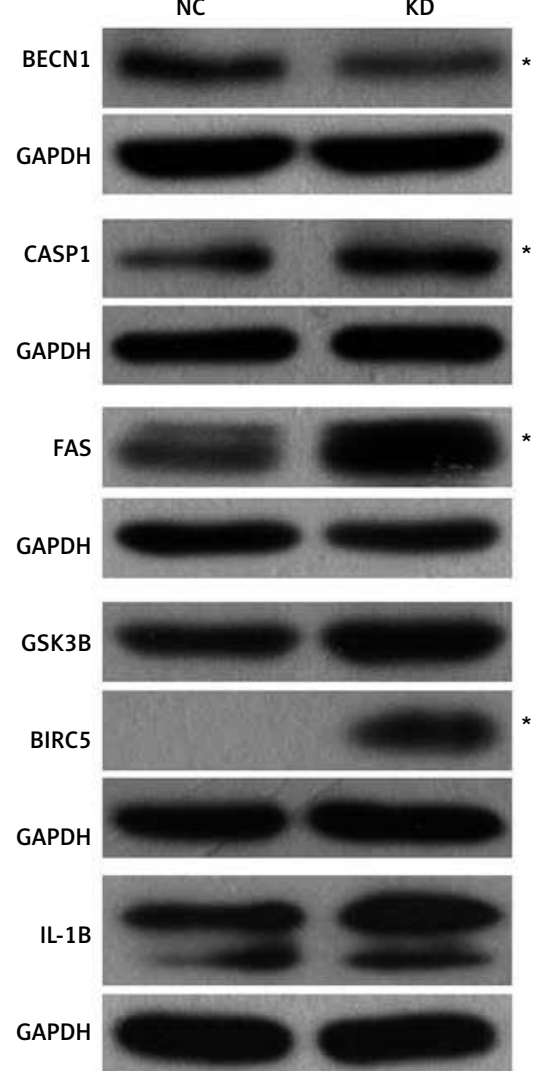

Figure 4. Cont. C - Interaction network. Upregulated genes are shown in red, and downregulated genes are shown in green. $\mathrm{D}$ - Potential downstream genes influenced by CALCOCO2 by IPA. E - Western blotting analysis Data are shown as mean $\pm S D\left(n=3 ;{ }^{*} p<0.05,{ }^{* *} p<0.01\right.$, and $\left.{ }^{* * *} p<0.001\right)$. 
tion and Crohn's disease [16]. However, its potential role in tumours, especially gliomas, remains a mystery. U87, U373, U251, and A-172 are common glioma cell lines in the cellular experiments. In the present study, we chose these four cell lines and selected the most abnormally expressed ones to verify the following experiments. Our results showed that CALCOCO2 is overexpressed in these four glioma cell lines, and the expression was highest in U87 and U251 cells, suggesting that it may be an important tumour-associated factor in the pathogenesis and progression of glioma. In the present study, CALCOCO2 was successfully silenced using a lentiviral vector, and the role of CALCOCO2 in cell growth and apoptosis was evaluated in U87 and U251 cell lines. Cell counting and MTT assays demonstrated that the silencing of $\mathrm{CALCOCO} 2$ significantly inhibited cell growth and proliferation. These results suggested that CALCOCO2 silencing had antitumor effects via its anti-proliferation functions.

In addition to proliferation, apoptosis also has a profound impact on the pathogenesis and progression of tumours. Apoptosis accomplishes programmed cell death via cell shrinkage and nuclear and DNA fragmentation [17]. Further, multiple human diseases are influenced by apoptosis, including tumours, immunological diseases, sepsis, and neurodegenerative changes [18-21]. Previous studies have demonstrated an important role of apoptosis in glioma; promoting apoptosis of glioma cells is a potential strategy for tumour therapy $[22,23]$. In this study, FCM and caspase-glo 3/7 assays indicated that tumour apoptosis increased significantly after CALCOCO2 silencing. Thus, apoptosis is a crucial mechanism by which CALCOCO2 influences gliomas.

To further assess the molecular mechanisms underlying CALCOCO2-associated glioma, the U87 glioma cell line was evaluated by a microarray analysis, and the results were analysed by IPA. The silencing of CALCOCO2 influenced the expression of hundreds of genes associated with various functions and diseases. CALCOCO2 was most strongly associated with cancer, supporting the important role of CALCOCO2 in gliomas. Other relevant functions, such as cell cycle, cell death and survival, cell growth, and proliferation, are also correlated with pathogenesis and progression [24, 25]. To further clarify the downstream biological alterations, several genes involved in cancer development were chosen, and a core $\mathrm{CALCOCO} 2$ network including multifarious genes related to cancer was mapped. Several cancer-related genes exhibited significant differential expression after the silencing of CALCOCO2. In particular, the wellknown pro-apoptosis genes FAS and CASP1 were significantly upregulated and the autophagy-re- lated gene BECN1 was markedly downregulated by $\mathrm{CALCOCO} 2$ silencing.

We then used western blotting to investigate the expression of BECN1, CASP1, FAS, GSK3B, $\mathrm{BIRC} 5$, and IL-1 $\beta$ at the protein level. FAS is a key death receptor; when combined with FasL, the conformation of FAS is altered, which then triggers the cascade reaction of apoptosis [26, 27]. Interleukin (IL)- $1 \beta$ (IL-1 $\beta$ ) is a cytokine in the family of chemokines, also known as lymphocyte stimulating factor [28]. In the cellular process, it is mainly produced by activated mononuclear macrophages and is related to immune response $[29,30]$. CASP1 plays a crucial role in innate immunity by activating the proinflammatory cytokine IL-1 $\beta$ [31]. GSK3 $\beta$ is a proline-guided serine/threonine protein kinase involved in energy metabolism, nerve cell development, and body morphogenesis [32]. BIRC5 is a member of the inhibitor of apoptosis (IAP) gene family, which encodes negative regulatory proteins that prevent apoptotic cell death $[33,34]$. It has been reported that activating CASP1, FAS, GSK3B, BIRC5, and IL-1 $\beta$ may induce cell apoptosis [35-39]. In this study, the protein levels of CASP1, FAS, GSK3B, $\mathrm{BIRC} 5$, and IL-1 $\beta$ were upregulated by the silencing of CALCOCO2, in accordance with the microarray results. These results suggested that the up-regulation of CASP1, FAS, GSK3B, BIRC5, and IL-1 $\beta$ induced by the inhibition of $\mathrm{CALCOCO} 2$ result in increased tumour apoptosis. In addition, we detected the significant downregulation of BECN1 after CALCOCO2 silencing. BECN1 is a key autophagy-promoting gene that maintains the balance between cell death and survival $[40,41]$. The activation of tumour autophagy is decreased using a BECN1-targeted microRNA [42]. Additionally, the size and number of breast carcinoma cells decrease after the knockdown of BECN1 [43]. Autophagy in tumour cells is activated in response to cellular stress [12]. The silencing of autophagy-related genes can decrease tolerance to extreme external conditions and even contribute to tumour cell death [44-46]. Previous studies have shown that there is a relationship between $\mathrm{CALCOCO} 2$ and autophagy $[13,15]$. The results of western blotting and gene microarray analyses in this study suggest that the mechanisms underlying CALCOCO2-mediated glioma pathogenesis and progression are also associated with autophagy.

In conclusion, the results of this study demonstrated that the knockout of CALCOCO2 could inhibit glioma by influencing autophagy and promoting apoptosis via the activation of FAS and CASP1.

\section{Acknowledgments}

This work is supported by the Education Department of Jilin Province (No. JJKH20190034KJ, Dr. Yuanyi Wang). 


\section{Conflict of interest}

The authors declare no conflict of interest.

\section{References}

1. Diao B, Liu Y, Zhang Y, Yu J, Xie J, Xu GZ. IQGAP1-siRNA inhibits proliferation and metastasis of U251 and U373 glioma cell lines. Mol Med Rep 2017; 15: 2074-82.

2. Hu GW, Wu L, Kuang W, et al., Knockdown of linc-OIP5 inhibits proliferation and migration of glioma cells through down-regulation of YAP-NOTCH signaling pathway. Gene 2017; 610: 24-31.

3. Zhao B, Zong G, Xie Y, Li J, Wang H, Bian E. Downregulation of ubiquitin-associated protein 2-like with a short hairpin RNA inhibits human glioma cell growth in vitro. Int J Mol Med 2015; 36: 1012-8.

4. Chen LF, Yang Y, Ma XD, et al. Optimizing the extent of resection and minimizing the morbidity in insular highgrade glioma surgery by high-field intraoperative MRI guidance. Turk Neurosurg 2017; 27: 696-706.

5. Li S, Chou AP, Chen W, et al. Overexpression of isocitrate dehydrogenase mutant proteins renders glioma cells more sensitive to radiation. Neuro Oncol 2013; 15: 57-68.

6. Guo H, He Y, Bu C, Peng Z. Antitumour and apoptotic effects of 5-methoxypsoralen in U87MG human glioma cells and its effect on cell cycle, autophagy and PI3K/ AKT signaling pathway. Arch Med Sci 2019; 15: 1530-8.

7. D’Amico RS, Englander ZK, Canoll P, Bruce JN. Extent of resection in glioma-a review of the cutting edge. World Neurosurg 2017; 103: 538-49.

8. Tseng YY, Su CH, Yang ST, et al. Advanced interstitial chemotherapy combined with targeted treatment of malignant glioma in rats by using drug-loaded nanofibrous membranes. Oncotarget 2016; 7: 59902-16.

9. Ding Y, Wang X, Pan J, et al. Aberrant expression of long non-coding RNAs (IncRNAs) is involved in brain glioma development. Arch Med Sci 2019; 16: 177-88.

10. Zhang S, Liang M, Naqvi NI, et al., Phototrophy and starvation-based induction of autophagy upon removal of Gcn5-catalyzed acetylation of Atg7 in Magnaporthe oryzae. Autophagy 2017; 13: 1318-30.

11. Bae SY, Byun S, Bae SH, Min DS, Woo HA, Lee K. TPT1 (tumor protein, translationally-controlled 1) negatively regulates autophagy through the BECN1 interactome and an MTORC1-mediated pathway. Autophagy 2017 13: 820-33.

12. Yang ZJ, Chee CE, Huang S, Sinicrope FA. The role of autophagy in cancer: therapeutic implications. Mol Cancer Ther 2011; 10: 1533-41.

13. Xie X, Li F, Wang Y, et al. Molecular basis of ubiquitin recognition by the autophagy receptor CALCOCO2. Autophagy 2015; 11: 1775-89.

14. Verlhac P, Viret C, Faure M. Dual function of CALCOCO2/ NDP52 during xenophagy. Autophagy 2015; 11: 965-6.

15. Jin S, Cui J. BST2 inhibits type I IFN (interferon) signaling by accelerating MAVS degradation through CALCOCO2directed autophagy. Autophagy 2018; 14: 171-2.

16. Till A, Lipinski S, Ellinghaus D, et al. Autophagy receptor CALCOCO2/NDP52 takes center stage in Crohn disease. Autophagy 2013; 9: 1256-7.

17. Yao Y, Li L, Huang X, et al. SERPINA3K induces apoptosis in human colorectal cancer cells via activating the Fas/FasL/ caspase-8 signaling pathway. FEBS J 2013; 280: 3244-55.

18. Yaacoub K, Pedeux R, Tarte K, Guillaudeux T. Role of the tumor microenvironment in regulating apoptosis and cancer progression. Cancer Lett 2016; 378: 150-9.
19. Girardot T, Rimmele T, Venet F, Monneret G. Apoptosis-induced lymphopenia in sepsis and other severe injuries. Apoptosis 2017; 22: 295-305.

20. Garg H, Joshi A. Host and viral factors in HIV-mediated bystander apoptosis. Viruses 2017; 9: 237.

21. Guler G, Ozgur E, Keles H, Tomruk A, Vural SA, Seyhan N. Neurodegenerative changes and apoptosis induced by intrauterine and extrauterine exposure of radiofrequency radiation. J Chem Neuroanat 2016; 75: 128-33.

22. Jane EP, Premkumar DR, Sutera PA, Cavaleri JM, Pollack IF. Survivin inhibitor YM155 induces mitochondrial dysfunction, autophagy, DNA damage and apoptosis in Bcl-xL silenced glioma cell lines. Mol Carcinog 2017; 56: 1251-65.

23. Shen ZG, Liu XZ, Chen CX, Lu JM. Knockdown of E2F3 inhibits proliferation, migration, and invasion and increases apoptosis in glioma cells. Oncol Res 2017; 25: 1555-66.

24. Diao J, Wu C, Zhang J, et al. Loss of diacylglycerol kinase-zeta inhibits cell proliferation and survival in human gliomas. Mol Neurobiol 2016; 53: 5425-35.

25. Liu H, Liang S, Yang X, et al. RNAi-mediated RPL34 knockdown suppresses the growth of human gastric cancer cells. Oncol Rep 2015; 34: 2267-72.

26. Zhou J, Song S, He S, et al. Silencing of decoy receptor 3 (DcR3) expression by siRNA in pancreatic carcinoma cells induces Fas ligand-mediated apoptosis in vitro and in vivo. Int J Mol Med 2013; 32: 653-60.

27. Lee GH, Kim HR, Chae HJ. Bl-1 enhances Fas-induced cell death through a $\mathrm{Na}+/ \mathrm{H}+$-associated mechanism. BMB Rep 2014; 47: 393-8.

28. Dinarello CA. Historical review of cytokines. Eur J Immunol 2007; 37: S34-S35.

29. Madej MP, Topfer E, Boraschi D, Italiani P. Different regulation of interleukin-1 production and activity in monocytes and macrophages: innate memory as an endogenous mechanism of IL-1 inhibition. Front Pharmacol 2017; 8: 335

30. Rosenwasser LJ. Biologic activities of IL-1 and its role in human disease. J Allergy Clin Immunol 1998; 102: 344-50.

31. Sollberger G, Strittmatter GE, Grossi S, et al. Caspase-1 activity is required for UVB-induced apoptosis of human keratinocytes. J Invest Dermatol 2015; 135: 1395-404.

32. Ginjupalli GK, Rice KM, Katta AN, et al. High-frequency electrical stimulation (HFES) data lean and obese Zucker rat tibialis anterior muscle: regulation of glycogen synthase kinase 3 beta (GSK3B) associated proteins. Data Brief 2017; 16: 423-9.

33. Narimani M, Sharifi M, Hakhamaneshi MS, et al. BIRC5 gene disruption via CRISPR/Cas9n platform suppresses acute myelocytic leukemia progression. Iran Biomed J 2019; 23: 369-78.

34. Abdi J, Rastgoo N, Chen Y, Chen GA, Chang H. Ectopic expression of BIRC5-targeting miR-101-3p overcomes bone marrow stroma-mediated drug resistance in multiple myeloma cells. BMC Cancer 2019; 19: 975.

35. Zhang X, Sha M, Yao Y, Da J, Jing D. Increased B-type-natriuretic peptide promotes myocardial cell apoptosis via the B-type-natriuretic peptide/long non-coding RNA LSINCT5/caspase-1/interleukin 1 beta signaling pathway. Mol Med Rep 2015; 12: 6761-7.

36. Matsushima S, Ishiyama J. MicroRNA-29c regulates apoptosis sensitivity via modulation of the cell-surface death receptor, Fas, in lung fibroblasts. Am J Physiol Lung Cell Mol Physiol 2016; 311: L1050-61.

37. Guo B, Zhang W, Xu S, Lou J, Wang S, Men X. GSK-3betA mediates dexamethasone-induced pancreatic beta cell apoptosis. Life Sci 2016; 144: 1-7. 
38. MacDonald JA, Kura N, Sussman C, Woods DC. Mitochondrial membrane depolarization enhances TRAIL-induced cell death in adult human granulosa tumor cells, KGN, through inhibition of BIRC5. J Ovarian Res 2018; 11: 89.

39. Jiang Y, Xie Z, Yu J, Fu L. Resveratrol inhibits IL-1betamediated nucleus pulposus cell apoptosis through regulating the PI3K/AKT pathway. Biosci Rep 2019; 39: BSR20190043.

40. Aita VM, Liang XH, Murty VV, et al. Cloning and genomic organization of beclin 1 , a candidate tumor suppressor gene on chromosome 17q21. Genomics 1999; 59: 59-65.

41. Cao Y, Klionsky DJ. Physiological functions of Atg6/ Beclin 1: a unique autophagy-related protein. Cell Res 2007; 17: 839-49.

42. Zhu H, Wu H, Liu X, et al. Regulation of autophagy by a beclin 1-targeted microRNA, miR-30a, in cancer cells. Autophagy 2009; 5: 816-23.

43. Gong C, Song E, Codogno P, Mehrpour M. The roles of BECN1 and autophagy in cancer are context dependent. Autophagy 2012; 8: 1853-5.

44. Sato K, Tsuchihara K, Fujii S, et al. Autophagy is activated in colorectal cancer cells and contributes to the tolerance to nutrient deprivation. Cancer Res 2007; 67: 9677-84.

45. Abedin MJ, Wang D, McDonnell MA, Lehmann U, Kelekar K. Autophagy delays apoptotic death in breast cancer cells following DNA damage. Cell Death Differ 2007; 14: 500-10.

46. Wu W, Ma J, Shao N, et al. Co-targeting IGF-1R and autophagy enhances the effects of cell growth suppression and apoptosis induced by the IGF-1R inhibitor NVPAEW541 in triple-negative breast cancer cells. PLoS One 2017; 12: e0169229. 